\title{
O processo de reciclagem do óleo lubrificante
}

A partir de uma abordagem envolvendo os conceitos de Ciclo de Vida do Produto e Logística Reversa, este artigo examina o processo de reciclagem do óleo lubrificante, derivado do petróleo, conhecido como re-refino. O óleo lubrificante usado apresenta um grande potencial poluidor e o re-refino, entre as diversas formas de reutilização desse resíduo, é a única que permite o retorno do óleo usado às suas características originais com qualidade equivalente. O trabalho examina o processo de re-refino praticado no Brasil em suas três etapas: coleta, processamento e comercialização. Constata a existência de deficiências sistêmicas e a necessidade de aprimoramento do sistema de logística reversa no processo de reciclagem de óleos lubrificantes, com benefícios em termos de racionalização do processo produtivo, agregação de valor ao produto e minimização dos impactos ambientais.

Palavras-chave: Reciclagem de Óleo Lubrificante; Re-refino; Ciclo de Vida do Produto; Logística Reversa.

\section{The lubricant oil recycling process} From an approach involving the concepts of Product Life Cycle and Reverse Logistics, this article examines the recycling process of oil derived
lubricant known as re-refine. The used lubricating oil presents a great potential polluter and the re-refine, among the several forms of
reutilization of this residue, is the only one that allows the return of the used oil to its original's characteristics with equivalent quality. The
paper examines the Brazilian re-refine process in its three stages: collection, processing and commercialization, and notes the existence of
systemic deficiencies and the need to improve the reverse logistics system in the recycling process of lubricating oils, with benefits in terms of
rationalization of the production process, aggregation of value to the product and minimization of environmental impacts.

Keywords: Recycling of Lubricating Oil; Re-refine; Product Life Cycle; Reverse Logistics.

Topic: Logística Reversa

Reviewed anonymously in the process of blind peer.

José Américo Martelli Tristão

Pontifícia Universidade Católica de São Paulo, Brasil

http://lattes.cnpq.br/9656467197446251

tristao@gvmail.br

Virgínia Talaveira Valentini Tristão

Universidade de São Paulo, Brasil.

http://lattes.cnpq.br/1753395514248966

vtalaveira@gmail.com

\section{Elias Frederico}

Universidade de São Paulo, Brasil.

http://lattes.cnpq.br/8661340733947250

elias.frede@gmail.com
Received: 11/10/2016

Approved: 14/01/2017

\section{Referencing this:}

TRISTÃO, J. A. M.; TRISTÃO, V. T. V.; FREDERICO, E.. O processo de reciclagem do óleo lubrificante. Revista Ibero-Americana de Ciências Ambientais, v.8, n.2, p.224-238, 2017. DOI: http://doi.org/10.6008/SPC2179-6858.2017.002.0018 


\section{INTRODUÇÃO}

Em todo o mundo, são gerados anualmente mais de 20 bilhões de litros de óleos lubrificantes usados. Se for considerado, com otimismo, que $60 \%$ desse volume é coletado e adequadamente utilizado, ainda existirão 8 bilhões de litros não coletados anualmente e sendo lançados nos lagos, rios, mares, oceanos, subsolo e atmosfera, poluindo a água potável e o ar que se respira. Além da poluição que pode causar ao meio ambiente, o óleo usado é um recurso que, se reciclado adequadamente, pode retornar à cadeia produtiva por ilimitadas vezes, sofrendo apenas as perdas de cada processamento, gerando consideráveis vantagens econômicas e poupando divisas, no caso de países, como o Brasil, que são importadores de básicos para lubrificantes. De acordo com média obtida pela API (American Petroleum Institute) junto às refinarias americanas, considerando o composto de subprodutos obtidos em seus processos, elas utilizam 84 litros de petróleo cru para produzir 1 litro de óleo básico virgem (o restante dos subprodutos são combustíveis, gases e petroquímicos), enquanto, com os mesmos 84 litros de óleo usado, são produzidos 55 litros de óleo rerefinado tão bom ou melhor que o virgem (conforme a Evergreen Oil Refinery-California, EUA) (HILSDORF, 1974).

Quando o óleo lubrificante é produzido a partir de básicos virgens (de primeiro refino), ele contém moléculas instáveis, principalmente aquelas contendo ligações duplas, que se oxidarão prioritariamente nas primeiras situações adversas. O óleo básico, originado de re-refino, quando processado adequadamente, não contém essas moléculas, que já foram oxidadas na primeira utilização e eliminadas no processo de re-refino. Daí se afirmar que o óleo básico re-refinado pode ter qualidade superior à de um básico de primeiro refino, por ser constituído de moléculas remanescentes com maior resistência à oxidação. Para se produzir óleo básico a partir de óleo usado, numa re-refinaria, consome-se apenas 33\% da energia que se gastaria para produzir a mesma quantidade de óleo básico a partir de petróleo cru, numa refinaria. No caso do re-refino, a tecnologia é bem restrita ao setor (devido aos desenvolvimentos específicos realizados em cada planta), o acesso às matérias-primas é garantido no Brasil por meio de portarias e resoluções do Conselho Nacional do Meio Ambiente (CONAMA), além de ter todas as condições para ser altamente competitivo em preços. Tem havido no Brasil, nos últimos anos, considerável progresso tecnológico no processo de re-refino, o que resulta em produto de melhor qualidade, reduzindo-se as restrições técnicas impostas à sua utilização. Entretanto, antes do processamento e comercialização do óleo usado, vem a etapa mais crítica que é a sua coleta. Neste trabalho, será analisado o processo completo, que é constituído por três etapas: coleta, processamento e comercialização. Entretanto, a coleta é o principal óbice ao crescimento da atividade de re-refino no Brasil e no mundo. O Brasil comercializa anualmente cerca de 1 bilhão de litros de lubrificantes e correlatos (óleos de têmpera, transferência de calor, transformador etc.) que geram cerca de 450 milhões/ano de óleos usados. Destes, cerca de 250 milhões deverão ser coletados para re-refino em 2006 e os restantes 200 milhões terão destinação desconhecida.

A correta administração desses resíduos é de suma importância para toda a sociedade, governo e entidades privadas, pelos ganhos que podem advir de sua reciclagem e pelos altos custos que serão evitados 
ao se impedir a contaminação de lençóis freáticos, rios, lagos, mares, atmosfera etc. O maior desastre ecológico com petróleo de que se tem notícia, o derramamento de petróleo cru do "Exxon Valdez", lançou 40 milhões de litros nas costas do Alaska. No Brasil, até 2005 foram descartados 200 milhões de litros por ano, poluindo nosso meio ambiente. Verdade que esse volume é distribuído por 12 meses e por todo o país, entretanto, mais da metade desses resíduos são lançados apenas na região sudeste, sendo cerca de 30 milhões no estado de São Paulo (quase um "Exxon Valdez" por ano) e o grau de periculosidade do óleo usado é várias vezes superior à do petróleo cru, devido às substâncias tóxicas contaminantes (chumbo, compostos clorados, óxidos de enxofre, ácidos diversos, etc.) muitas delas de comprovada ação cancerígena. Muito se tem feito, nos últimos anos, no Brasil, principalmente em termos de legislações que punem e coíbem os descartes incorretos, mas muito se tem ainda por fazer, com mais rapidez, no que diz respeito à coleta, que passa por uma questão cultural e sofre pela falta de uma estrutura nacional para recolhimento desses resíduos. As regiões Norte, Nordeste e Centro-Oeste, juntas, geram cerca de 100 milhões de litros/ano de óleo usado e não possuem sequer uma re-refinaria em operação. A falta de alternativa do que fazer com esses resíduos pode estar conduzindo-os aos rios, subsolo e atmosfera, resultado da queima indiscriminada.

Conforme descrito na Norma NBR-10004 da ABNT "Anexo A" - Resíduos perigosos de fontes não especificadas (SÓLIDOS, 1997), o óleo usado é um resíduo perigoso, classificação esta adotada pelos mais importantes órgãos de controle ambiental em todo o mundo. Dessa forma, o óleo usado não pode ser lançado no meio ambiente nem ser queimado "in natura", devido aos contaminantes nele contidos (compostos clorados, metais pesados etc.). Sua queima só pode ocorrer de forma controlada e após processo de remoção desses contaminantes.

Os óleos lubrificantes atingem o fim de sua vida útil, quando perdem suas características originais, por contaminação interna ou externa, oxidação ou depleção dos aditivos. Os óleos usados, de base mineral, não são biodegradáveis e podem provocar danos irreparáveis ao meio ambiente se descartados de forma inadequada. Os lubrificantes usados possuem diferentes tipos de contaminantes, dependendo de sua origem, tais como: produtos de oxidação (borras, gomas, lacas e vernizes), metais de desgaste (ferro, cobre, alumínio, estanho, etc.), metais componentes dos aditivos (zinco, fósforo, cloro, chumbo, enxofre etc.), água, hidrocarbonetos leves (provenientes de combustíveis não queimados), ácidos formados na combustão, sílica (poeira) etc. Os lubrificantes usados são considerados responsáveis por $10 \%$ da poluição observada nos mares do mundo (LIMA, 1974).

\section{DISCUSSÃO TEÓRICA}

\section{Avaliação do ciclo de vida do produto}

O ciclo de vida físico de um produto, segundo Fiksel (1997), é uma sequência de atividades que compreende desde a concepção do produto, as transformações de materiais e energia, como a extração e beneficiamento de matérias primas, a movimentação e transporte desses materiais, a fabricação do produto, o transporte até o local onde será utilizado, a sua reutilização ou reciclagem, até a sua disposição final ao 
término da sua vida útil, por esta razão este conceito é também conhecido pela expressão do "berço ao túmulo". Todas essas etapas que constituem o Ciclo de Vida do produto, quando analisadas permitem identificar os aspectos ambientais e os impactos potenciais a serem gerados ao longo da vida deste produto. Em cada uma dessas etapas pode haver consumo de energia e de recursos naturais, assim como pode ocorrer a geração de resíduos ou emissões que podem provocar impactos ambientais. A ferramenta que permite o desenvolvimento de uma forma sistemática desse tipo de análise é um instrumento de gestão ambiental denominado Avaliação do Ciclo de Vida (ACV), que se aplica a determinado produto ou serviço.

A Avaliação do Ciclo de Vida (ACV) se apresenta como uma ferramenta importante de aprimoramento do processo produtivo e dos produtos de uma empresa. Sua abordagem do ciclo integral de vida do produto permite a identificação e avaliação das etapas críticas do processo industrial. A ACV permite estimar os impactos potenciais cumulativos resultantes de todas as fases do processo produtivo, incluindose, de um modo geral, aqueles impactos desconsiderados nos outros processos tradicionais de análise. A inclusão desses impactos permite uma observação mais abrangente dos aspectos ambientais dos produtos ou processos e uma noção mais exata das efetivas trocas ambientais na seleção de produtos. Assim, a ACV facilita os tomadores de decisão a melhor selecionar seus produtos e processos de forma a causar o mínimo impacto ao meio ambiente. Esses dados podem ser utilizados juntamente com outros fatores, tais como custos e dados de performance, para uma melhor seleção de produtos e processos.

Este instrumento pode ser entendido como um método no qual a energia, os materiais utilizados e os diversos tipos de emissões relacionados com determinado produto ou serviço específico são mensurados, analisados e atribuído ao ciclo de vida completo a partir de um ponto de vista ambiental (TSOULFAS; PAPPIS, 2006). As informações da ACV identificam as transferências dos impactos ambientais de um meio para outro (por exemplo, a eliminação de uma emissão para o ar acarretando uma emissão de efluentes para a água) ou de um estágio do ciclo de vida para outro (por exemplo, do uso ou reuso do produto para a fase anterior de aquisição de matérias-primas). Sem a realização de uma $A C V$, tais transferências podem não ser identificadas e adequadamente incluídas nas análises, já que estão fora dos objetivos típicos das análises tradicionais ou do foco dos processos de seleção de produtos.

Por exemplo, em uma decisão entre duas alternativas de produtos utilizando-se critérios puramente ambientais, a escolha pode recair sobre a alternativa 1 por gerar menos resíduo sólido que a alternativa 2 . Entretanto, após a realização de uma ACV, pode-se concluir que a alternativa 1 implica, na realidade, em maior impacto ambiental para todo o ciclo de vida do que quando o impacto produzido nos três meios (ar, água e terra) é medido, podendo, por exemplo, provocar maior nível de emissões químicas durante a fase de manufatura. A indústria tem utilizado essa ferramenta para:

desenvolver avaliação sistemática das consequências ambientais associadas com determinado produto;

analisar trocas ambientais associadas com um ou mais produtos ou processos específicos para se obter dos responsáveis pela decisão, como, por exemplo, a comunidade ou o governo, a aprovação para implementar alguma ação planejada; 
quantificar as emissões ambientais para a atmosfera, água e terra referente a cada estágio do ciclo de vida do produto ou ao processo que contribui de forma mais relevante com as diversas poluições;

avaliar os efeitos dos consumos de materiais e emissões ambientais sobre o homem e meio ambiente;

identificar áreas de oportunidade que gerem maior eficiência econômica; desenvolver e criar produtos.

Para que a ACV produza resultados confiáveis e, acima de tudo, comparáveis, é necessário que os impactos ambientais associados às interações mencionadas sejam avaliados por meio de metodologias e procedimentos sistemáticos e padronizados. Por essa razão, a International Organization for Standardization (ISO) desenvolveu uma família de normas internacionais estabelecendo orientações e requisitos para a realização de avaliações do ciclo de vida. Disponibilizadas como normas brasileiras através da ABNT, as normas NBR ISO 14040, ABNT NBR ISO 14041, 14042 e 14043 padronizam e estabelecem requisitos para todas as fases de elaboração de uma ACV: A avaliação completa e consistente da eficiência ecológica de um produto exige que os impactos sejam considerados ambientalmente adequados em todas as etapas de seu ciclo:

A norma 14040 especifica a estrutura geral, princípios e requisitos básicos para conduzir e relatar estudos de avaliação do ciclo de vida;

A norma 14041 especifica os requisitos e os procedimentos necessários para a elaboração do objetivo e do escopo de uma ACV e para a elaboração, interpretação e comunicação de um Inventário de Ciclo de Vida (ICV). A fase de inventário de uma ACV corresponde à coleta e tratamento dos dados e informações, qualitativos e quantitativos, sobre os fluxos de materiais e energia envolvidos nas diversas interações com o meio ambiente que ocorrem no ciclo de vida de um produto ou serviço;

A norma 14042 descreve e fornece orientações para avaliação dos impactos ambientais associados aos diversos fluxos de materiais e de energia identificados e tratados na fase de inventário;

A norma 14043 estabelece requisitos e recomendações para a interpretação de uma ACV, envolvendo aspectos como análise dos resultados obtidos, explicitação de conclusões e recomendações e comunicação desses resultados de forma adequada às partes interessadas na Avaliação.

A relevância do estímulo à aplicação dessa ferramenta no Brasil está também relacionada à necessidade de se assegurar a competitividade de nossas exportações já que eventuais barreiras poderão ser impostas, principalmente pelos países europeus, através da exigência de rotulagem ambiental dos produtos brasileiros com base na avaliação do seu ciclo de vida.

\section{Logística Reversa}

Enquanto a logística tradicional se preocupa em garantir o fluxo do produto do fabricante ao consumidor, a Logística Reversa se preocupa com o retorno do produto à sua origem, seja ele um lubrificante usado, uma bateria de celular usada, um pneu ou uma embalagem PET. Historicamente, os fabricantes não se consideravam responsáveis pelo que acontecia com seus produtos e embalagens após o seu consumo. Atualmente, com o surgimento de legislações rigorosas sobre proteção ambiental e maior conscientização ecológica dos consumidores, os fabricantes passaram a se preocupar com o descarte dos refugos gerados em 
sua linha de produção, bem como com o acompanhamento de todo o ciclo de vida de seu produto, incluindo as embalagens, após a venda. Muitos produtos que apresentam potencial de dano ao meio ambiente ainda são descartados ou incinerados de forma inadequada, poluindo o solo, mananciais ou atmosfera.

Segundo Rogers e Tibben-Lembke (1999), Logística Reversa é o processo de "planejamento, implementação e controle do fluxo eficiente e de baixo custo de matérias primas, estoque em processo, produto acabado e informações relacionadas, desde o ponto de consumo até o ponto de origem, com o propósito de recuperação de valor ou descarte apropriado para coleta e tratamento de lixo". Segundo o grupo universitário de estudo da Logística Reversa REVLOG (2006), os principais motivos para as empresas implementarem a Logística Reversa são: a) Legislação Ambiental, que obriga as empresas a retornarem seus produtos/embalagens e promoverem o tratamento adequado, b) benefícios econômicos do uso dos produtos que retornam ao processo de produção, evitando-se o alto custo do descarte correto dos resíduos, c) a crescente conscientização ambiental dos consumidores. Além dessas razões, Rogers et al. (1999) ainda listam algumas razões estratégicas, como: razões competitivas, como diferenciação por serviço; limpeza do canal de distribuição; proteção da margem de lucro; e recuperação de valor e de ativos.

Um planejamento de Logística Reversa envolve basicamente os mesmos elementos que constituem um plano logístico convencional. Embora muitas empresas prefiram terceirizar essa área de atividades, é desejável que as equipes responsáveis pelas logísticas tradicional e reversa sejam independentes, já que os fluxos com os quais elas lidam são muito diferentes. A maioria dos analistas acredita que, tendo em vista o processo irreversível da globalização, as empresas multinacionais tendem a adotar, em todos os países onde operam os mesmos procedimentos operacionais previstos nas legislações ambientais mais rigorosas dos países europeus mais desenvolvidos, o que promoverá em pouco tempo a sua implementação também no Brasil. No processo de Logística Reversa, as empresas se tornam responsáveis pelo retorno de seus produtos, seja para reciclagem ou para descarte apropriado, portanto, sua formação de custos deve ter uma abordagem bem ampla, como é o caso do "Custeio do Ciclo de Vida Total", que permite a administração dos custos desde o início do Planejamento e Desenvolvimento ( P\&D) até o término do serviço de suporte ao cliente. Considerando o processo de Logística Reversa, este ciclo será estendido ao retorno do produto ao ponto de origem. Portanto, já na fase de desenvolvimento do produto, deve-se levar em consideração a forma como se dará o descarte e/ou a sua reciclagem após o fim de sua vida útil (ZACHARY, 1996).

As montadoras de automóveis, bem como empresas de alta tecnologia, como IBM e Xerox, são exemplos de empresas que desenvolvem seus produtos já pensando nessa última etapa. O estabelecimento dos postos de coleta garante o retorno dos produtos aos pontos de origem ou aos locais de descarte adequados. Embora o mesmo sistema utilizado na logística convencional possa ser também utilizado na Logística Reversa, o normal é que sejam planejados dois sistemas distintos, devido às peculiaridades e divergências inerentes aos dois processos. No caso, por exemplo, da indústria de bebidas, o sistema utilizado na Logística Reversa é o mesmo da logística convencional, já que os vasilhames são recolhidos nos mesmos estabelecimentos onde são distribuídos os cheios e envolvem as mesmas pessoas. Entretanto, no caso de baterias de telefones celulares usadas, ou de latas de alumínio, o retorno nem sempre ocorre utilizando a 
mesma via. A devolução ou descarte poderá ocorrer muito tempo após a venda, e utilizando outros canais de coleta. Como o conceito de Logística Reversa, com a visão moderna de redução de custos e proteção ambiental, é relativamente novo, muitas empresas procuram aproveitar a estrutura já existente em sua logística tradicional para implementar a Logística Reversa. De uma maneira geral, as empresas têm enfoque diferente quanto à Logística Reversa. Muitas delas, embora a pratiquem rotineiramente, seja quando recebe um produto de volta, como devolução ou para assistência técnica, seja quando adquire algum material reciclável para utilizar como matéria-prima, não aplicam o conceito de Logística Reversa nem consideram esse processo como parte importante de suas atividades. No entanto, não se concebe mais um sistema logístico eficiente e completo que não contemple essa atividade como uma parte fundamental. Outras empresas implementam a Logística Reversa e procuram otimizar seus processos, buscando uma redução em seus custos de produção, obter uma vantagem competitiva, ou melhorar sua imagem institucional junto aos seus consumidores. Por outro lado, existem empresas para quem a Logística Reversa não passa de mais um custo, na maioria das vezes exigida por lei, sobre a qual devem manter um rígido controle, implementandoa no limite das responsabilidades estabelecidas pela legislação. Nesse último caso se encontram os fabricantes de óleos lubrificantes, de pneus, de agrotóxicos etc. (PONCE, 2000; SINDIRREFINO, 2000; REVELOG, 2006).

Ainda não existe no Brasil uma legislação suficientemente abrangente sobre o assunto, como ocorre na Europa, principalmente na Alemanha, pioneira na regulamentação dos descartes de resíduos. Alguns produtos no país têm o seu descarte regulamentado por órgãos como o CONAMA e a Agência Nacional de Petróleo (ANP). Entretanto, independente de legislações específicas, o Brasil possui hoje, segundo o Sebrae, 2361 empresas atuando no setor de reciclagens diversas, incluindo recicladores, sucateiros, coletadores, cooperativas e associações. A maioria delas (1145) está concentrada no Sudeste. Segundo o Sebrae e o CEMPRE (Compromisso Empresarial para a Reciclagem), grande parte das empresas que atuam nesse setor é de micro e pequeno porte, foco das ações do Sebrae. Estima-se que as empresas que movimentam esse mercado geram 500 mil postos de trabalho.

De acordo com o CEMPRE, o país recicla cerca de 10\% de seus resíduos sólidos urbanos, incluindo 97\% de latas de alumínio (recorde mundial), 49\% de latas de aço, 48\% de PET, 46\% das embalagens de vidro, 79\% de papelão e $39 \%$ dos pneus produzidos.

\section{Aspectos técnicos do re-refino}

Os óleos lubrificantes representam cerca de $2 \%$ do total de derivados de petróleo e são os únicos que podem ser mantidos com as características originais, exercendo suas funções durante períodos tão longos como 20 anos ou mais em unidades seladas (CARRETEIRO, 1987). Os demais derivados de petróleo são utilizados como combustíveis ou matéria prima em indústrias químicas, sendo consumidos ou perdendo suas características originais na primeira utilização. Um óleo lubrificante produzido com básicos virgens, isto é, de primeiro refino, contém moléculas instáveis, principalmente aquelas contendo ligações duplas, que se oxidarão prioritariamente nas primeiras situações adversas. Por outro lado, o óleo básico proveniente de re- 
refino, quando processado adequadamente, não contém essas moléculas, que já foram oxidadas na primeira utilização e eliminadas no processo de re-refino. Pode-se afirmar, portanto, que o óleo básico re-refinado pode ter qualidade superior à de um básico de primeiro refino, por ser constituído de moléculas remanescentes com maior resistência à oxidação (RUNGE, 1994).

Os lubrificantes perdem a capacidade de exercer sua função devido à presença de contaminantes internos ou externos, bem como pela depleção dos aditivos. Entretanto, submetidos a tratamentos apropriados de regeneração, como o re-refino, eles retornam à sua condição inicial de óleo básico, podendo participar de um novo ciclo, e assim sucessivamente por um número indeterminado de vezes. Para se produzir óleo básico a partir de óleo usado, numa re-refinaria, se consome apenas 33\% da energia que se gastaria para produzir a mesma quantidade de óleo básico a partir de petróleo cru, numa refinaria (CIORA, 1999; CLUER, 1987).

Aos cerca de $60 \%$ dos óleos usados que são coletados no mundo, são dadas diferentes destinações, em cada país, dependendo de uma série de variáveis, como: volume total coletado, concentração e distribuição dessa coleta, tecnologia de reciclagem disponível etc. Em alguns países, como os EUA, parte do óleo usado coletado recebe um tratamento para desidratação e remoção de sólidos e é queimado, principalmente em fornos de cimento e usinas termoelétricas. Essa destinação tem como desvantagem a reutilização do óleo, que é um produto nobre, apenas uma vez, já que ele é queimado como combustível. Para atender aos requisitos técnico-ambientais para queima, de modo a não poluir a atmosfera, o óleo usado tem que estar com os contaminantes dentro dos limites estabelecidos pelas normas internacionais de segurança para queima controlada de óleos usados (RAMSDEN, 2002).

Algumas empresas, principalmente indústrias grandes consumidoras de lubrificantes, regeneram em suas próprias instalações o óleo usado, através de processos físico-químicos que eliminam os contaminantes. Em seguida o óleo é re-aditivado e volta para seus equipamentos originais ou é utilizado em outras aplicações. Esse processo tem a vantagem de proporcionar perdas pequenas em cada processamento, mas não se aplica a óleo de motor, pela sua elevada degradação. O óleo lubrificante utilizado em motores deve, necessariamente, ser encaminhado para re-refino.

\section{O óleo re-refinado}

Existem inúmeras razões econômicas, ambientais e técnicas pelas quais o óleo re-refinado vem, paulatinamente, ganhando participação no mercado de óleo lubrificante dos EUA. Os lubrificantes rerefinados são frequentemente competitivos em preço, atendem à demanda dos consumidores preocupados com o meio ambiente e atingem o mesmo padrão de qualidade do produzido com óleo virgem. Os governos local, estadual e federal, a U. S. Postal Service e muitas companhias privadas estão usando lubrificantes rerefinados em vários tipos de veículos, desde leves até equipamentos pesados (GARTHE, 1994)

A tecnologia de re-refino avançou muito desde o tempo em que se regenerava o óleo simplesmente pela remoção de água, poeira, borra e alguns compostos voláteis. Hoje, o óleo re-refinado passa por um processo bastante similar ao que passa o petróleo cru numa refinaria. As etapas básicas de um processo de 
re-refino incluem destilação a vácuo e hidrotratamento. Nos EUA e Canadá, a tecnologia MOHAWK é usada por três companhias: Mohawk, Safety-Kleen e Evergreen, para produzir óleo básico re-refinado. Óleos lubrificantes feitos de básicos re-refinados têm que passar pelos mesmos testes e atender aos mesmos padrões de desempenho daqueles feitos com óleo virgem, para receber a certificação do American Petroleum Institute (API). Fabricantes de veículos e de motores, tais como Ford, Chrysler, General Motors, Mercedes Benz e Detroit Diesel têm dado certificados de garantia que permitem o uso de óleo re-refinado, desde que atendam aos padrões API. Muitos testes de campo com óleo re-refinado têm sido realizados pelas National Bureau of Standards, U. S. Army, Department of Energy, U. S. Postal Service e Environmental Protection Agency. Esses estudos concluíram que o óleo re-refinado é equivalente ao óleo virgem, que ele pode passar por todos os testes exigidos e, eventualmente, superar o óleo virgem. A composição química do óleo re-refinado e do óleo virgem se mostraram tão similar que a análise química de laboratório concluiria que eles são idênticos. De acordo com o National Recycling Coalition Recycled Business Alliance, se todos os americanos coletassem seu óleo usado para re-refino, isso manteria 35 milhões de veículos rodando por ano, reduziria a dependência de óleo importado, aumentaria o número de empregos e reduziria o déficit comercial em US\$150 milhões. Como os primeiros métodos para regeneração de óleos usados datam dos anos 20 e não produziam óleos de boa qualidade, ainda existem muitos conceitos errôneos de que o óleo rerefinado hoje é inferior em qualidade ao óleo básico virgem.

Três companhias na América do Norte produzem óleos básicos re-refinado que, após formulados com aditivos diversos, se transformam em extensa gama de lubrificantes (LUBRIZOL,1999). Essas companhias, Safety-Kleen em Chicago (IL), Evergreen em Newark (CA) e Mohawk em Vancouver (Canadá), usam a mesma tecnologia para re-refinar óleo usado. Suas plantas juntas possuem uma capacidade diária de 5.800 barris. 0 óleo re-refinado produzido por essas três refinarias na América do Norte atende aos padrões do API. Em adição ao óleo básico re-refinado produzido na América do Norte, os EUA ainda importam óleo re-refinado da Espanha, Grécia, Coréia e outros. Atualmente, existem várias marcas de óleo re-refinado disponível nos EUA, como, Safety-Kleen America's Choice, Rosemead SOAR, Chevron Eco, 76 Products Firebird, - Lyondell Enviroil. A percentagem de óleo re-refinado no produto varia dependendo do fabricante e do tipo de óleo lubrificante. Por exemplo, 76 Products e Rosemead comercializam um 15W-40 (óleo de motor) que contém 100\% básico re-refinado. Safety-Kleen America's Choice 10W-30 e 10W-40 (óleos de motor), contém de 70 a 100\% de básico re-refinado. Outras marcas contêm diferentes percentuais, dependendo do produto.

\section{Processo "Mohawk" de re-refino}

O processo Mohawk de re-refino é o único processo até agora que produz lubrificantes que atendem aos padrões do API. Esse processo é usado por três re-refinarias nos EUA e Canadá, já referidas anteriormente. O processo Mohawk emprega o processo de pré-tratamento, destilação de água e hidrocarbonetos leves, destilação de combustível diesel, destilação de asfalto flux, hidro acabamento. 
Este processo Mohawk foi projetado para aceitar óleo usado de uma grande variedade de fontes. A carga, usualmente, inclui qualquer produto como fluidos de transmissão, óleo de engrenagem, graxa, óleo hidráulico, óleo de usinagem de metais e óleos de motor. O óleo usado é coletado dos geradores (postos de serviços, mecânicas, indústrias etc.) e testado com relação à presença de substâncias perigosas e outros parâmetros. Então ele é transportado para a re-refinaria, onde é testado novamente e bombeado para os tanques de matérias-primas. A primeira etapa no processo Mohawk separa a água e o combustível contaminante do componente lubrificante. A água constitui, tipicamente, $10 \%$ do coletado e o combustível (hidrocarbonetos leves) até cerca de 3\%. O combustível diesel é removido na segunda etapa de destilação. O diesel, que atinge até $7 \%$ do material coletado, pode ser queimado na planta, como combustível, ou vendido para uso em fornos e caldeiras industriais. A terceira etapa separa os materiais pesados, tais como poeira, metais, aditivos e outros contaminantes. Este subproduto obtido (asfalto flux) é usado como asfalto, vedação de coberturas etc. Livre de água, combustível e aditivos, o destilado lubrificante passa através de uma fina película evaporadora e depois para o hidrotratamento. Na última etapa do processo Mohawk de re-refino, gás hidrogênio e catalisadores são misturados com a fração remanescente de resíduos para remover enxofre e outros produtos de oxidação. Cerca de $65 \%$ do óleo usado original permanece no fim do processo como óleo básico acabado. Esse óleo ainda é separado, por destilação, em dois produtos: neutro leve e neutro pesado, os quais, combinados com aditivos e outros básicos, darão origem aos diversos lubrificantes disponíveis no mercado.

\section{O processo de re-refino de óleos lubrificantes no cenário mundial}

Em todo o mundo são consumidos anualmente cerca de 45 bilhões de litros de lubrificantes, que dão origem a mais de 20 bilhões de litros de óleos usados. Se considerarmos, de modo otimista, que $50 \%$ desse volume são coletados e utilizados adequadamente, ainda restarão 10 bilhões de litros não coletados, sendo lançados nos rios, mares, subsolo e atmosfera (se queimados inadequadamente), poluindo o meio ambiente. Para enfrentar esse problema, a maior parte dos países desenvolvidos e, portanto, os maiores consumidores do produto, vêm adotando políticas de gestão ambiental no sentido de incentivar a reciclagem do produto.

Portugal consome anualmente cerca de 100 milhões de litros de lubrificantes, dos quais cerca de $60 \%$, após o uso, são recicláveis. Entretanto, apenas $30 \%$ são recolhidos por empresas licenciadas, com destinação adequada. Os restantes $30 \%$ são coletados no mercado paralelo e sua destinação pode ser a queima ilegal em fornos industriais ou padarias, embora seja proibido, sem qualquer tipo de tratamento. A principal deficiência do sistema português de reciclagem de óleos lubrificantes é a inexistência de uma rede de pontos de coleta em todo o país. Em Portugal não existem re-refinarias.

Os Estados Unidos geram cerca de 5 bilhões de litros de lubrificantes usados anualmente. Desse total, aproximadamente $60 \%$ são coletados e $40 \%$ descartados de forma imprópria, gerando forte poluição. No caso do óleo coletado, sua destinação prioritária é a queima controlada, sendo que apenas $8 \%$ é re-refinado. O restante é reciclado através de tratamentos simples de descontaminação e reutilizado. A Environmental Protection Agency - USEPA recomenda a todos os órgãos do governo que deem preferência à compra de 
óleos lubrificantes que contenham um mínimo de $25 \%$ de óleos básicos re-refinados, observadas as condições de preço e qualidade. Por solicitação governamental, as montadoras Ford, General Motors, Caterpillar, Chrysler e Detroit Diesel, aprovam e utilizam lubrificantes produzidos com óleo básico rerefinado, desde que atendam as especificações da American Petroleum Institute - API. No estado da Pennsylvania foi criado um sistema voluntário de locais de coleta, denominados Used Oil Collection Sites UOC's. A situação é especialmente grave na região da Grande Los Angeles, Califórnia, onde mais de 80 milhões de litros de óleo de motor usados são lançados anualmente no meio ambiente. Para coibir o descarte ilegal de óleo usado impõe-se uma multa que pode chegar a US\$250 mil.

A Alemanha pode ser apontada como o país mais avançado em termos de coleta e re-refino de óleo usado. Lá são consumidos anualmente cerca de 1,4 bilhão de litros de lubrificantes, dos quais $60 \%$ são coletados após o uso, e desses, $65 \%$ são re-refinados. Os pontos de comercialização são obrigados a ter um ponto de coleta de óleo usado e embalagens vazias. O país conta com uma das legislações mais rigorosas quanto ao controle ambiental e apresenta a maior taxa de re-refino de óleo usado.

Na Itália a coleta de óleo usado é administrada pelo Consortium, uma entidade mantida conjuntamente por órgãos governamentais e empresas de petróleo e re-refino. Os produtores de lubrificantes pagam uma taxa aos responsáveis pela coleta, que encaminham os óleos para a reciclagem, combustão, re-refino ou incineração. O Consortium vende o óleo usado para empresas de re-refino.

A França aplica uma taxa especial sobre os básicos virgens produzidos ou importados, com a finalidade de financiar a coleta dos óleos usados. Os detentores de óleo usado devem entregá-lo aos coletores sem qualquer encargo, ficando os custos de remoção a cargo da Agência de Controle Ambiental que destina parte ao re-refino, cerca de $45 \%$, e o restante, cerca de $55 \%$, para a queima, principalmente em indústrias cimenteiras e usinas termoelétricas.

\section{O processo de re-refino no Brasil}

Entre 1978 e 1988, o Brasil chegou a coletar 190 milhões de litros anuais de óleo lubrificante utilizado, volume superior ao que estava coletando no final da década de 90, 180 milhões de litros anuais. As várias mudanças na legislação fiscal introduzidas pelo governo nesse período agiram como fator ora de estímulo ora de desestímulo às atividades de coleta e re-refino do óleo usado. Neste período estava em vigor o Imposto Único - IU para petróleo e derivados, sendo dada isenção para o re-refino. Desse modo, o rerefinador pagava pelo óleo usado um valor que inibia a sua utilização como combustível, estimulava a sua armazenagem pelos pontos geradores e proporcionava margem suficiente para sua comercialização a preços inferiores aos do óleo novo. Com a extinção do imposto único e, consequentemente, da vantagem fiscal que gozava o óleo re-refinado, a coleta de óleo usado declinou $30 \%$ nos quatro anos subsequentes, permanecendo na faixa dos 130 milhões de litros/ano.

Outro complicador para a indústria do re-refino foi a integração da Petrobrás na economia globalizada, com a internacionalização dos preços dos óleos básicos para o mercado interno, que era, para o neutro pesado, produto mais consumido, cerca de US\$1000/m3 em 1988 e caiu para cerca de US\$ 480/m3 
em 1992. Dessa forma, os re-refinadores perderam a capacidade de comprar o óleo usado que passou a concorrer com o óleo combustível BPF (baixo ponto de fluidez) e os geradores passaram a dar outras destinações ao produto, principalmente à queima descontrolada em fundições e outros fornos de pequenas indústrias.

Quando, em 1992, a Agência Nacional de Petróleo criou o Frete de Uniformização de Preços (FUP), elevou artificialmente os preços dos óleos básicos virgens em cerca de 50\%. Com esse diferencial de preço, o setor de re-refino conseguiu sobreviver até setembro de 1997, quando o FUP foi extinto, em decorrência da desregulamentação do setor petrolífero. Esse procedimento tornou-se inevitável devido às necessidades de se adequar às regras do Mercosul, bem como, tornar-se competitivo numa economia globalizada.

Em novembro de 1997, pela Portaria Interministerial no 4, foi criado um grupo de trabalho para analisar a situação do re-refino e particularmente da coleta. Esse grupo sugeriu uma fase de transição, que se prolongou até setembro de 1999, sendo que todos os fabricantes de lubrificantes associados ao Sindicato Nacional das Empresas Distribuidoras de Combustíveis e Lubrificantes (SINDICOM) se comprometeram a comprar o óleo re-refinado a preços superiores aos do óleo novo, em volumes proporcionais preestabelecidos, até que se encontrasse uma solução definitiva para o problema. A partir de outubro de 1999, por determinação da Portaria n. 125 da ANP, foi estabelecido o princípio do poluidor pagador e os produtores e importadores de lubrificantes assumiram a responsabilidade pelo custo da coleta. No primeiro ano, até setembro de 2000 , deveria ser coletado $20 \%$ do volume total de óleo comercializado, a partir de outubro de 2000 , esse percentual passou para $25 \%$ e, desde outubro de 2001 , foi fixado o limite mínimo de $30 \%$ do volume comercializado.

Em agosto de 2007 foi publicada a Portaria Interministerial MME/MMA 464/07 determinando os percentuais mínimos de recolhimento do óleo lubrificante usado ou contaminado que deve ser recolhido pelos produtores e importadores que atendem o mercado nacional, com vigência a partir de 2008. As exigências são definidas para cada região do país e alteradas progressivamente, como demonstra a tabela I.

Tabela 1: Percentuais regionais de coleta

\begin{tabular}{ccccccc}
\hline Ano & Nordeste & Norte & Centro Oeste & Sudeste & Sul & Total \\
\hline $\mathbf{2 0 0 8}$ & $19 \%$ & $17 \%$ & $27 \%$ & $42 \%$ & $33 \%$ & $33,40 \%$ \\
$\mathbf{2 0 0 9}$ & $21 \%$ & $20 \%$ & $29 \%$ & $42 \%$ & $34 \%$ & $34,20 \%$ \\
$\mathbf{2 0 1 0}$ & $23 \%$ & $23 \%$ & $31 \%$ & $42 \%$ & $35 \%$ & $35,00 \%$ \\
$\mathbf{2 0 1 1}$ & $25 \%$ & $24 \%$ & $31 \%$ & $42 \%$ & $35 \%$ & $35,90 \%$ \\
\hline
\end{tabular}

Em 2012 o percentual mínimo de coleta e destinação do óleo usado ou contaminado em todo o país foi elevado para 36,9\%. Nos três anos seguintes, esta exigência passou para 37,4\%, em 2013,38,1\%, em 2014, e 38,5\%, em 2015. As regiões com os percentuais mínimos mais elevados são o Sudeste e Sul, que atingi em 2015 o patamar de $42 \%$ e 37\%, respectivamente. Em seguida estão as regiões Centro-Oeste (35\%), Nordeste (32\%) e Norte (31\%), cujos percentuais foram elevados paulatinamente.

\section{Avaliação dos resultados do processo de reciclagem do óleo lubrificante utilizado no Brasil}

Conforme dados do SINDICOM, o Brasil comercializa anualmente cerca de um bilhão de litros de lubrificante. Deste volume, $60 \%$ se destinam à aplicação automotiva, incluindo desde motocicletas, 
automóveis e caminhões até equipamentos agrícolas e de construção, como tratores. Nesse segmento se utiliza não apenas como óleo de motor, mas também para transmissões mecânicas e automáticas, sistemas hidráulicos, freio úmido etc. Os restantes $40 \%$ destinam-se à indústria. Do consumo total de um bilhão de litros, são gerados cerca de 450 milhões de litros de óleos usados.

Embora a legislação vigente determine que seja coletado um mínimo de $30 \%$ do óleo produzido, apenas $25 \%$ ou cerca de 250 milhões de litros estão sendo coletados para re-refino. Os 200 milhões restantes têm destinação desconhecida, sendo o fim mais provável a queima in natura ou o descarte direto no meio ambiente, como demonstra a figura 3. O potencial poluidor do óleo descartado foi salientado no relatório apresentado pelo grupo de trabalho do SINDICOM, em 1997 (ARAUJO, 1997). O relatório aponta os seguintes dados: os lubrificantes usados são considerados responsáveis por $10 \%$ da poluição observada nos mares do mundo; pesquisas realizadas em universidades, concluem que 1 litro de óleo usado é capaz de contaminar 1 milhão de litros de água potável; ambientalistas afirmam que o descarte de uma tonelada de óleo usado, despejada em mares, rios e lagos causa dano equivalente aos esgotos domésticos de uma cidade com 40 mil habitantes; apenas 5 litros de óleo usado podem recobrir uma superfície de $5000 \mathrm{~m} 2$ de um lago, matando seus organismos por asfixia; a queima de óleo usado sem um pré-tratamento pode lançar na atmosfera compostos clorados e sulfurados, monóxido de carbono, dioxinas, metais pesados (chumbo, cromo, cádmio, zinco) e vários tipos de substâncias tóxicas e corrosivas, algumas com ações cancerígenas; e apenas 10 kg de óleo usado, quando queimado de forma descontrolada e sem pré-tratamento, podem jogar no ar até $20 \mathrm{~g}$ de metais pesados, potencialmente cancerígenos.

Por outro lado, o óleo usado é um recurso que, se reciclado adequadamente, pode retornar à cadeia produtiva por ilimitadas vezes, sofrendo apenas as perdas de cada processamento, gerando consideráveis vantagens econômicas e poupando divisas, no caso de países que, como o Brasil, são importadores de básicos para lubrificantes. Se coletado e re-refinado, o óleo usado pode gerar até $70 \%$ de óleo básico de alta qualidade, pronto para reiniciar o ciclo que pode se repetir indefinidamente.

Mais da metade de todo o lubrificante consumido no Brasil ocorre na região sudeste, liderada pelo Estado de São Paulo, que detém o maior parque industrial do país e mais da metade da frota nacional de veículos em circulação. As regiões norte, nordeste e centro-oeste juntas consomem $25 \%$ dos lubrificantes no Brasil, gerando mais de 100 milhões de litros de óleo usado por ano. As longas distâncias até uma re-refinaria e a pulverização dos pontos de consumo dificultam a coleta e encaminhamento dos resíduos para o re-refino. De acordo com o "Diagnóstico Ambiental da Baia de Ilha Grande", publicado em dezembro de 1997 pela Secretaria de Estado do Meio Ambiente do Rio de Janeiro, em parceria com o Ministério do Meio Ambiente, dos Recursos Hídricos e da Amazônia Legal, cerca de 24.000 litros de óleo usado são despejados anualmente nas águas costeiras da Baía de Ilha Grande, por cerca de 1.200 embarcações de pequeno porte mantidas em ancoradouros, cais e marinas. Quando o óleo lubrificante é trocado, o óleo usado é despejado no mar ou, quando levado para terra, é despejado no solo ou esgoto. Segundo esse diagnóstico, a situação é tão grave que em cerca de 100 quilômetros da orla da Baía de llha Grande existem indícios de exposição crônica a óleo flutuante, com manchas nas pedras e destruição quase total da fauna e da flora da zona entre marés. 
Podemos observar também que o processo de re-refino, em suas três etapas - coleta, processamento e comercialização - vem enfrentando problemas. A indústria de re-refino, que já chegou a contar com mais de 30 empresas, hoje está reduzida a 10, com uma capacidade nominal total de 300 milhões de litros por ano, sendo que apenas uma dessas empresas, a Lwart situada em Lençóis Paulista no Estado de São Paulo, é responsável por cerca de $50 \%$ de toda a coleta e re-refino no país.

\section{CONCLUSÃO}

Embora o óleo lubrificante usado seja um resíduo de elevado potencial poluidor, sua reciclagem através de métodos modernos de re-refino pode reconduzi-lo à cadeia produtiva por infinitas vezes, preservando esse recurso não renovável, protegendo o meio ambiente e economizando divisas. No mundo são consumidos anualmente cerca de 45 bilhões de litros de lubrificantes, dos quais, após o uso, cerca de 8 bilhões de litros não são coletados e são lançados nos mares, rios, esgotos e atmosfera, contaminando o meio ambiente.

No Brasil esse consumo anual é de cerca de 1 bilhão de litros, que geram 450 milhões de litros de óleo usado, dos quais 200 milhões não são coletados e têm destinação desconhecida. 0 descarte inadequado ou a utilização incorreta desses resíduos (como a queima "in natura") provoca danos ambientais irreparáveis. A adoção de políticas públicas ambientais, intensificada na última década, tem colaborado para a redução do problema, mas tem se mostrado ainda insuficiente para a sua solução. A criação da Agência Nacional de Petróleo, junto com as demais agências reguladoras, veio se somar ao CONAMA, na aplicação de medidas coercitivas que visam reduzir o impacto ambiental desses resíduos. Entretanto, a cada dia mais se consolida a concepção de que a solução definitiva para o problema exige uma visão multidisciplinar do assunto, envolvendo Educação Ambiental, Responsabilidade Social das empresas, técnicas modernas de Logística Reversa e Análise do Ciclo de Vida do produto, processos físico-químicos de re-refino que não gerem resíduos descartáveis etc. Algumas re-refinarias no Brasil e no mundo já conseguem obter óleo re-refinado de ótima qualidade, equivalente ao óleo virgem, sem descartar qualquer subproduto poluente, que são utilizados como insumos ou matérias-primas para processos subsequentes. Em todo o mundo e particularmente no Brasil, pela sua dimensão geográfica e ampla pulverização dos pontos de consumo, a coleta do óleo usado se constitui no maior óbice à priorização do re-refino no processo de reciclagem. A logística reversa de resíduos que agregam valor econômico à cadeia produtiva, como o alumínio, ferro, pneus e PET, proporciona maior estímulo à sua realização, independente de ações coercitivas do poder público, pela atrativa remuneração aos seus agentes coletores, armazenadores e reprocessadores.

Verifica-se a necessidade de desenvolvimento e avaliação dos conceitos de ciclo de vida e logística reversa no processo de reciclagem de óleos lubrificantes, com benefícios em termos de racionalização do processo produtivo, agregação de valor ao produto e minimização dos impactos ambientais. 


\section{REFERÊNCIAS}

ABNT. Resíduos sólidos: ABNT/NBR 10004. Rio de Janeiro, 1997.

ARAÚJO, M. A. S.. Reciclagem de óleos lubrificantes. Rio de Janeiro: CENPES, 1997.

CARRETEIRO, R. P.; MOURA, C. R. S.. Lubrificantes e Lubrificação. São Paulo: Makron Books, 1987.

CIORA, R. J.; LIU, P. K. T.. Final report: a Low-Cost Environmentally Benign Waste Lubricant

Recycling/Rerefining Tecnnollogy. EPA, 1999.

CLUER, A.. Used Lube Oil Disposal-Global Overview. Petroleum Review, 1994.

FIKSEL, J.. Ingeniería de diseño medioambiental: DEF: desarrollo integral de productos y procesos ecoeficientes. Madrid: McGrawHill, 1997.

GARTHE, J. W.; KOWAL, P. D.. Recycling Used Oil. Pennstate, 1994.

HILSDORF, J. W.. Química Tecnológica: lubrificação e lubrificantes. São Paulo: 1974

LIMA, L. R.. Elementos básicos de engenharia química. São Paulo: McGraw-Hill, 1974.

LUBRIZOL. Future directions. Cleveland, 1999.
PONCE, N.. Informe de La primera reunión: del comité coordinador regional de la red panamericana de manejo ambiental de residuos (REPAMAR). Quito: 2000.

RAMSDEN, D. P.. Responsible management of used lubricants by closed-Loop recycling. Evergreen, 2002.

ROGERS, D. S.; TIBBEN-LEMBKE, R. S.. Going backwards: reverse logistics tends and practices. University of Nevada, 1999.

RÜGER, K. F.. Reflexões sobre a viabilidade do desenvolvimento sustentado. São Paulo: Ecotech, 1999.

RUNGE, P.; DUARTE, G., GEMPERLÉ, R.. Lubrificação automotiva. São Paulo: Triboconcept, 1994.

RUNGE, P.; DUARTE, G.. Lubrificantes nas indústrias. São Paulo: Triboconcept, 1989.

SINDIRREFINO. Newsletter. São Paulo, 2000.

TSOULFAS, G. T.; PAPPIS, C. P.. Environmental principles applicable to supply chains design and operation. Journal of Cleaner Production, v.14, p.1593-1602, 2006.

ZACHARY, J. E. Rerrefined motor oil: overcoming the Myths. Santa Bárbara: Sigrid Wright, 1996. 